\title{
INFORMAÇÃO E DIVISÃO DO TRABALHO NO TERRITÓRIO BRASILEIRO: ALGUMAS CARACTERÍSTICAS DO SETOR DE SEGUROS E RESSEGUROS
}

Resumo: Assistimos na atualidade a uma profunda transformação do território em virtude da emergência do meio técnico-científico-informacional. Neste contexto, a informação adquire novo significado, tornando-se uma variável de fundamental importância para a organização e estratégia dos agentes hegemônicos. Vale destacar que uma das características do período atual é o crescente nível de riscos e incertezas. Assim, a análise do setor de seguros e resseguros é de fundamental importância, uma vez que essas atividades oferecem garantias contra diversos riscos, intensificam a produção de informações e contribuem com o aprofundamento da divisão social e territorial do trabalho.

Palavras-chave: Seguros. Resseguros. Setor de Serviços. Informação. Território Brasileiro.

\section{INFORMATION AND THE DIVISION OF LABOR IN THE BRAZILIAN TERRITORY: SOME CHARACTERISTICS OF THE INSURANCE AND REINSURANCE INDUSTRY}

Abstract: We are currently witnessing a profound transformation of the territory due to the emergence of a technical-scientific-informational milieu. Within this context, information acquires new meaning, becoming a variable of fundamental importance for the organization and strategy of hegemonic agents. It should be mentioned that one of the characteristics of the current period is the increasing level of risks and uncertainties. Thus, an analysis of the insurance and reinsurance industry is of fundamental importance, since these activities offer guarantees against several risks, intensify the production of information and contribute to deepening the social and territorial division of labor.

Keywords: Insurance. Reinsurance. Service Sector. Information. Brazilian Territory.

\section{INFORMACIÓN Y DIVISIÓN DEL TRABAJO EN EL TERRITORIO BRASILEÑO: ALGUNAS CARACTERÍSTICAS DEL SECTOR DE SEGUROS Y REASEGUROS}

Resumen: Asistimos en la actualidad a una profunda transformación del territorio debido a la emergencia del medio técnico-científico-informacional. En este contexto, la información adquiere nuevo significado, convirtiéndose en una variable de fundamental importancia para la organización y estrategia de los agentes hegemónicos. Cabe destacar que una de las características del período actual es el creciente nivel de riesgos e incertidumbres. Así, el análisis del sector de seguros y reaseguros es de fundamental importancia, ya que estas actividades ofrecen garantías frente a diversos riesgos, intensifican la producción de información y contribuyen a la profundización de la división social y territorial del trabajo.

Palabras clave: Seguros. Reaseguros. Sector Servicios. Información. Territorio Brasileño.

\footnotetext{
1 Universidade Federal da Integração Latino-Americana - UNILA, Instituto Latino-Americano de Tecnologia, Infraestrutura e Território, Foz do Iguaçu, Brasil, leandro.trevisan@unila.edu.br, https://orcid.org/0000-0001-5860-0541.
} 


\section{Introdução}

Podemos considerar a Revolução Industrial como um ponto de inflexão na história humana; a partir deste evento, o homem pôde, cada vez mais, se livrar das amarras da natureza e transformar o meio em que vive.

Conforme Montalbán (1971, p.34), este momento também parece ser crucial na evolução histórica da informação.

Se bem que a invenção da arte de imprimir e o desenvolvimento do comércio e do correio marcassem o início da etapa evolutiva da informação, foi o aparecimento da industrialização e, como ela, de todas as características do mundo moderno, que lhe deram o seu caráter actualíssimo.

A análise da informação no mundo atual nos evidencia como esta variável se tornou um recurso estratégico para a reprodução do capital em escala mundial. "A relação existente entre o dinheiro e a informação faz com que se queira integrá-la no mundo dos interesses da finança ligados inteiramente à defesa do sistema económico capitalista" (ibid., p.39-40).

Vale destacar que, no período atual, as dinâmicas socioespaciais possuem um elevado nível de riscos ${ }^{2}$ e incertezas (SILVA, 2005); além disso, é preciso considerar que os territórios são, do ponto de vista dos capitais modernos, irracionais, uma vez que neles coexistem diversos agentes com inúmeros interesses (CASTILLO e FREDERICO, 2010).

Desta forma, com o intuito de diminuir esta "irracionalidade", os agentes hegemônicos (Estados e empresas) buscam se munir, dentre outros elementos, com grandes volumes de informação, fazendo desta variável um recurso estratégico.

Com o intuito de melhor compreender o papel da variável informação no período atual, Silva $(2001 ; 2005 ; 2012)$ apresenta uma tipologia, distinguindo as informações produtivas das informações banais.

Sendo fundamental para a competitividade das grandes empresas, a elaboração das informações produtivas revela uma dinâmica aparentemente contraditória; se, por um lado, tais informações passam a ser produzidas em volumes crescentes, por outro, sua circulação é seletiva. Além disso, é preciso destacar que estas informações são direcionadas ao uso dos agentes hegemônicos,

\footnotetext{
${ }^{2}$ No contexto da atividade de seguros/resseguros, o "risco" pode ser definido como um "evento futuro e incerto, de natureza súbita e imprevista, independente da vontade do Segurado, cuja ocorrência pode provocar prejuízos de natureza econômica" (Circular SUSEP 347/07).
} 
uma vez que se tornaram uma mercadoria cara devido à complexidade de sua elaboração e às potencialidades de seu uso.

Esta questão remete à difícil tarefa de se definir o valor daquilo que é intangível. Para Dantas (2002, p.142-143) o valor de uso da informação estaria ligado à poupança de tempo de trabalho, bem como à "ação que ela proporciona ao agente receptor".

De maneira complementar, podemos dizer que o valor da informação (produtiva) estaria relacionado aos níveis de inteligência organizacional possibilitados aos agentes que dela fazem uso, ou seja, esta informação (enquanto recurso estratégico) vai auxiliar na definição das melhores estratégias frente a territórios e sociedades cada vez mais complexas. Em última instância, as possibilidades advindas do uso da informação levarão à precificação desta variável.

Já as informações banais (produzidas em grande medida pelos meios de comunicação de massa), possuem ampla difusão, se capilarizando pelo território (SILVA, 2001; 2005; 2012); é justamente esta ampla difusão que define sua importância para os agentes hegemônicos, pois possibilita a formação de opiniões condizentes com seus interesses.

\begin{abstract}
A clara contradição que decorre de qualquer sistema económico baseado na liberdade de empresa mais uma vez se evidencia: toda a gente é livre de comprar máquinas compositoras, rotativas, bobinas de papel, teleimpressores, etc. - mas apenas os adquirem aqueles que dispõem de meios para tal. Consequência: não informa quem quer informar, mas sim quem pode dispor dos meios necessários a essa operação (MONTALBÁN, 1971, p.27).
\end{abstract}

Além disso, aponta Montalbán (ibid., p.40) que "a informação é uma técnica de formação da opinião pública, e o monopólio da opinião revela-se a forma mais eficiente de domínio".

Aqui, podemos dizer ainda que, à medida que a difusão da informação (seja ela produtiva ou banal) se torna instantânea e simultânea - por meio das modernas redes de comunicação, amparadas em satélites, cabos de fibra ótica etc. (CASTILLO, 1999) - se ampliam, igualmente, os contextos da globalização por todo o planeta.

Contudo, é preciso considerar que, além das informações que atingem os lugares verticalmente (e em grande quantidade), existe também a informação fruto das relações que se processam horizontalmente, no cotidiano (SILVA, 2012).

Neste contexto, cabe ressaltar o papel desempenhado pelas diversas formas de manifestação cultural, rádios comunitárias, jornais de bairro etc. Mais do que isso, 
é preciso considerar a importância adquirida pela internet (ainda que seu acesso seja seletivo) como fonte de informação alternativa à grande mídia.

Até agora, o espaço público de comunicação era controlado através de intermediários institucionais que preenchiam uma função de filtragem e de difusão entre os autores e os consumidores de informação: estações de televisão, de rádio, jornais, editoras, gravadoras, escolas, etc. Ora, o surgimento do ciberespaço cria uma situação de desintermediação, cujas implicações políticas e culturais ainda não terminamos de avaliar (LEVY, 1998, p.45).

Assim, esta informação (processada e difundida horizontalmente) tem enorme valor, uma vez que pode se colocar como uma variável contra hegemônica, servindo como meio de resistência aos interesses exógenos e se colocando aos reais interesses da população que habita um determinado lugar.

\section{Serviços e Informação}

Tradicionalmente, a economia é dividida em três grandes setores: primário, secundário e terciário; busca-se, assim, diferenciar a maneira como se processa o trabalho do homem.

Os setores econômicos caracterizam-se pela incidência do trabalho humano, representado pela ação de produzir ou de se apropriar, transformar, executar e conceber bens materiais e não materiais, capazes de representar um valor econômico para a satisfação das necessidades humanas (TOMELIN, 1988, p.56).

Para Tomelin (ibid.), os três setores clássicos (primário, secundário, terciário) podem ser caracterizados da seguinte forma: a) setor primário - "se caracteriza pela produção ou pela apropriação de bens com o concurso do reino animal, vegetal e mineral, sendo a agricultura a sua atividade dominante" (p.63); b) setor secundário "se caracteriza pela transformação de uma matéria-prima em produto pronto para ser utilizado. A atividade por excelência é a indústria" (p.66); c) setor terciário "caracteriza-se simplesmente como um setor de execução das atividades auxiliares no complexo da economia: sua atividade dominante são os serviços" (p.68).

Vale destacar que o setor de serviços, durante muito tempo, foi visto como de menor importância, com fraca produtividade; além disso, costumeiramente, era definido por exclusão: era classificado como terciário tudo aquilo que não se encaixava nos setores primário e secundário.

Contudo, ressalta Kon (1999, p.65) que "o papel e a natureza das atividades de serviços vêm sofrendo mudanças consideráveis a partir da recente 
reestruturação produtiva das empresas e das economias mundiais e particularmente com o apoio da inovação tecnológica"3.

Assim, diante da grande complexidade que envolve a divisão do trabalho atual, alguns autores começaram a questionar esta divisão clássica e passaram a analisar as transformações de ordem quantitativa e qualitativa sofridas pelo setor terciário. Neste contexto, diversas propostas buscaram estabelecer subdivisões dentro deste setor ou mesmo a criação de um novo setor.

É justamente em relação a esta última perspectiva (da criação de um novo setor) que iremos estruturar nossa discussão. Assim, nos chama a atenção as propostas que visam selecionar/agrupar as atividades informacionais e com alto conteúdo científico e tecnológico.

Neste sentido, Tomelin (1988) debate a conformação de um novo setor na economia: o setor quaternário; para este autor (ibid., p.71) o setor quaternário se caracteriza "[...] pela ação de conceber, criar, interpretar, organizar, dirigir, controlar e transmitir, com a intervenção do ambiente científico e técnico, atribuindo a esses atos um valor econômico".

Para Silva (2001, p.06) "as novas atividades produtoras de informação, agrupadas no setor quaternário da economia, são centrais à elaboração e coordenação das múltiplas redes planetárias".

Para Tomelin (1988, p.74),

A expressão maior do setor quaternário é a organização. Esta reagrupa não somente o capital, mas também todos os mecanismos capazes de bem orientar a produção, desde os seus menores componentes até o domínio da técnica existente. É conveniente acrescentar que a organização é capaz de fazer produzir ou de criar o que ainda não existe. E o quaternário, com sua característica dominante de criação.

Existem, ainda, pesquisadores debruçados sobre o entendimento do papel reservado aos serviços intensivos em informação e conhecimento no período atual, valendo-se da terminologia Serviços Intensivos em Conhecimento (SIC), ou, para fazer menção ao termo em inglês, Knowledge-Intensive Business Services (KIBS).

Em linhas gerais, Freire (2006) caracteriza os Serviços Intensivos em Conhecimento da seguinte forma: a) tem participação expressiva no valor adicionado; b) utilizam recursos humanos altamente qualificados em comparação a

\footnotetext{
${ }^{3}$ Kon (1999) mostra como diversos autores (Fischer, 1939; Clark, 1940; Sabolo, 1975; Fuchs, 1968, entre outros) buscaram caracterizar os setores da economia.
} 
outros setores da economia; c) atuam como fontes primárias de informação e de conhecimento, fornecem tecnologias de informação e auxiliam em processos de inovação; d) proporcionam alta interação produtor - usuário.

Dentre os vários serviços classificados como intensivos em informação e conhecimento (Porat, 1977; Eurostat ${ }^{4}$ ), nos chama a atenção os serviços de seguros e resseguros. Porat (1977, p.34) $)^{5}$ aponta que

a companhia de seguros, para vender sua mercadoria, deve engajarse em uma grande quantidade de trabalho de diagnóstico, analítico e atuarial.

Vale ressaltar que tais serviços, além de produzirem uma grande quantidade de informações e conhecimentos (muitos dos quais de base territorial), contribuem, ainda, com o processo de financeirização do território.

Isto posto, buscaremos, a seguir, apresentar algumas das características do setor de seguros e resseguros, bem como sua conformação no território brasileiro.

\section{Algumas Definições e Aspectos da Atividade de Seguros e Resseguros}

Antes de apresentarmos um panorama da configuração atual do setor de seguros e resseguros no território brasileiro, julgamos necessário apresentar algumas definições básicas relacionadas a este setor ${ }^{6}$.

Longe de esgotar os termos e definições que competem a este setor, buscaremos, a seguir, apresentar alguns elementos necessários ao entendimento da discussão que segue; primeiramente, torna-se fundamental a apresentação das definições de seguro e resseguro.

O seguro se constitui no

contrato mediante o qual uma pessoa denominada Segurador, se obriga, mediante o recebimento de um prêmio, a indenizar outra pessoa, denominada Segurado, do prejuízo resultante de riscos futuros, previstos no contrato (Circular SUSEP 354/07).

Um ponto de partida do funcionamento da atividade seguradora pauta-se no princípio do mutualismo ${ }^{7}$. Assim, esta atividade está alicerçada na ideia de que cada

\footnotetext{
${ }^{4}$ Autoridade Estatística da União Europeia. Disponível em: http://ec.europa.eu/eurostat/statisticsexplained/index.php/Glossary:Knowledge-intensive services (KIS) .

5 Tradução Livre.

6 Para tanto, buscamos tais informações no Portal da Susep - Superintendência de Seguros Privados, autarquia vinculada ao Ministério da Fazenda. http://www2.susep.gov.br/bibliotecaweb/glossario.aspx . Acesso em 26/01/2017.

7 "[...] atualmente, existem três grandes grupos de seguros diferentes. Os seguros de danos; os seguros de capitalização; os seguros mistos, que adotam os conceitos das duas primeiras categorias
} 
indivíduo de um grupo contribua de modo proporcional (prêmio) ${ }^{8}$, face aos riscos que todos correm (potencialmente) e aos sinistros que certamente afetarão parte dos indivíduos deste grupo ${ }^{9}$.

O seguro é, assim, uma atividade que se funda na idéia de solidariedade e no rateio prévio do custo da reparação, dispensando proteção efetiva para todos os que contribuírem para a formação do fundo indenizatório (MAGALHÃES, 1997, p.11).

Outro elemento importante para o funcionamento desta atividade é a sua capilaridade; uma vez que as companhias de seguros/resseguros precisam respeitar sua capacidade de retenção de riscos, os excedentes são transferidos para outra companhia. Este processo pode se repetir várias vezes até que o risco esteja completamente diluído (MENDONÇA, 2010).

Desta forma, estas considerações remetem ao princípio do resseguro e da retrocessão. Assim, o resseguro se constitui na

operação de transferência de riscos de uma cedente [Seguradora], com vistas a sua própria proteção, para um ou mais resseguradores, através de contratos automáticos ou facultativos (Resolução CNSP 168/07).

Já a retrocessão é definida como a

operação de transferência de riscos de resseguro de resseguradores, com vistas a sua própria proteção, para resseguradores ou para sociedades seguradoras locais, através de contratos automáticos ou facultativos (Resolução CNSP 168/07).

No que se refere às receitas de uma companhia seguradora, Mendonça (2010) explica que ela tem, basicamente, duas fontes: o negócio de aceitar riscos e a remuneração do capital e das reservas da companhia; assim, como apontamos anteriormente, "[...] uma seguradora é também uma importante investidora no mercado de capitais e no mercado financeiro" (ibid., p. 77).

Feitas estas considerações iniciais, nos remetemos a outras questões relativas ao funcionamento da atividade seguradora. Qual é, afinal, o produto de uma seguradora? Como é calculado seu preço?

Sendo uma mercadoria intangível, o produto de uma seguradora está expresso nas cláusulas componentes da apólice de seguro ${ }^{10}$; trata-se, assim, de

em suas apólices. Os seguros de danos são os que se baseiam no mutualismo" (MENDONÇA, 2010, p.75).

8 Prêmio - Importância paga pelo Segurado ou estipulante/proponente à Seguradora para que esta assuma o risco a que o Segurado está exposto. (Circular SUSEP 306/05).

9 "A certeza é dada pela teoria do risco, pela lei dos grandes números, e pelas tábuas estatísticas que medem a ocorrência e a frequência dos eventos segurados" (MENDONÇA, 2010, p.73). 
garantir ao segurado a reparação do prejuízo sofrido, em decorrência de um sinistro, conforme estipulado neste documento.

Caso não ocorra o sinistro no prazo e nas condições estipuladas na apólice, o segurado nada receberá de retorno.

[...] a companhia de seguros vende uma mercadoria chamada "segurança" para pessoas avessas ao risco. O cliente compra uma medida de utilidade, ou benefício, derivado da presciência que caso ocorra qualquer evento indesejável contratualmente especificado, o cliente (ou vítima) será compensado pela companhia de seguros (PORAT, 1977, p.34) $)^{11}$.

A contratação desta "segurança" ou "garantia" de ressarcimento futuro (observadas as condições expressas na apólice) implica um custo para o segurado. Assim, para o cálculo do "preço da apólice" (prêmio), alguns fatores devem ser considerados.

Partindo do princípio da mutualidade, Mendonça (2010) explica, ainda, que os seguros são divididos por carteiras, ou seja, é realizado um agrupamento com base em riscos semelhantes, o que torna o cálculo do prêmio mais justo. Segue o autor apontando que, "com base na lei das probabilidades, é possível quantificar as perdas médias do grupo, por frequência e valor, e com base nelas, precificar o custo de um seguro, em função do risco de cada segurado" (ibid., p. 73-74).

Assim, além dos cálculos de probabilidade, também é produzida uma série de informações sobre o indivíduo, sobre o bem a ser segurado, a maneira como o bem é utilizado, em relação às características do lugar onde se encontram o indivíduo e o bem segurado, potenciais prejuízos etc.

Além disso, é preciso considerar, também, as características de cada seguradora (estrutura organizacional, gastos etc.). Esses elementos, em conjunto, ajudam a explicar as variações nos preços dos seguros dentro de uma mesma carteira ou de uma seguradora para outra.

De forma simplificada, a conta que uma seguradora faz para precificar suas apólices é somar os sinistros com as despesas administrativas, comerciais e tributárias, acrescer ao resultado mais um percentual que será seu lucro, e dividir o total encontrado de forma proporcional a cada risco entre seus segurados (ibid., p.82).

\footnotetext{
${ }^{10}$ Apólice - Documento que formaliza o contrato de seguro, estabelecendo os direitos e as obrigações da sociedade seguradora e do segurado e discriminando as garantias contratadas. (Circular SUSEP no 308/05).

11 Tradução Livre.
} 
As informações expostas até aqui evidenciam a grande complexidade que envolve a atividade em questão; assim, vale ressaltar que, face ao crescimento do mercado segurador/ressegurador, bem como à necessidade de se produzir um amplo conjunto de dados e informações, as companhias do setor buscam, cada vez mais, profissionais altamente qualificados (sobretudo para trabalhar com apólices complexas).

Garcia (2015) ${ }^{12}$ aponta que, para Mario Pinto (diretor de ensino superior da Escola Nacional de Seguros - ENS), "[...] a falta de capacitação dos executivos e corretores muitas vezes faz com que seguros sejam mal desenhados para as necessidades dos clientes", o que pode resultar em apólices mais caras e que não atendam exatamente àquilo que o cliente precisa.

Diante do exposto, consideramos a atividade seguradora/resseguradora como algo extremamente complexo, pois, além de utilizar mão-de-obra qualificada (entre outros elementos) para se estabelecer o valor a ser pago pelo segurado (prêmio), esta atividade, para se realizar, leva à elaboração, processamento, armazenamento e transmissão de um grande volume de dados e informações. Assim, consideramos que as companhias seguradoras e resseguradoras se constituem como agentes do setor quaternário da economia.

\section{O Setor de Seguros e Resseguros no Território Brasileiro}

A análise do setor de seguros no território brasileiro aponta bons resultados nos últimos anos. O "Mercado de Seguros Gerais" vem apresentando crescente arrecadação; passou de $R \$ 22,5$ bilhões em 2005 para $R \$ 37,6$ bilhões em 2010, atingindo a cifra de $\mathrm{R} \$ 57$ bilhões em 2013 (FENSEG, 2017, p.01) ${ }^{13}$.

Vale destacar, contudo, que, embora venha apresentando crescimento constante, o mercado de seguros no Brasil apresenta uma participação no PIB $(3,2 \%)$ bastante inferior se comparado ao de países como EUA $(8,1 \%)$, Reino Unido $(11,8 \%)$ e França $(9,5 \%)$ [KPMG, Jan/2013).

Em 2011, existiam no território brasileiro cerca de 115 companhias seguradoras e 69.672 corretores de seguros ativos (DELLOITE, 2011).

Abaixo, podemos visualizar as 15 maiores companhias de seguros (ramos gerais) atuantes no território brasileiro (em prêmios emitidos líquidos) no ano de 2018 (Quadro 01).

12 Disponível em: www.revistacobertura.com.br/lermais materias.php?cd materias=105425\&friurl=:Setor-procura-mao-de-obra-mais-qualificada- . Acesso em 31/01/2017.

${ }^{13}$ http://cnseg.org.br/fenseg/ 
Quadro 01 - As 15 Maiores Seguradoras - Ramos Gerais - Brasil/2018

\begin{tabular}{|c|l|c|c|}
\hline Classificação & \multicolumn{1}{|c|}{ Companhia } & Sede & $\begin{array}{c}\text { Prêmios Emitidos } \\
\text { Líquidos (em R\$ } \\
\text { milhões) }\end{array}$ \\
\hline 1 & Bradesco Seguros * $^{*}$ & RJ & $38.005,1$ \\
\hline 2 & SulAmérica * & RJ & $19.654,7$ \\
\hline 3 & Porto Seguro & SP & $15.271,3$ \\
\hline 4 & Mapfre Seguros Gerais & SP & $6.402,9$ \\
\hline 5 & Caixa Seguros & DF & $5.927,6$ \\
\hline 6 & Tokio Marine & SP & $5.154,9$ \\
\hline 7 & Seguradora Lider-DPVAT & RJ & $4.669,1$ \\
\hline 8 & Zurich Minas Brasil & MG & $3.697,0$ \\
\hline 9 & Allianz do Brasil ${ }^{*}$ & SP & $3.622,7$ \\
\hline 10 & Liberty Mundial ${ }^{*}$ & SP & $3.599,7$ \\
\hline 11 & HDI Seguros & SP & $3.424,6$ \\
\hline 12 & Itaú Seguros & SP & $3.347,3$ \\
\hline 13 & Sompo Seguros & SP & $2.937,3$ \\
\hline 14 & Chubb Seguros & SP & $2.444,1$ \\
\hline 15 & Brasilveículos & SP & $1.426,1$ \\
\hline
\end{tabular}

* Balanço Consolidado ou Combinado.

Fonte: Valor Econômico ${ }^{14}$

Aqui, mais uma vez, evidenciamos como as companhias de seguros se tornaram agentes do mercado financeiro, não apenas por serem investidoras, mas, também, pela estreita relação que algumas seguradoras possuem com alguns dos principais bancos instalados no Brasil (Bradesco, Banco do Brasil, Caixa, Itaú).

Vale destacar também que a maior complexidade das relações sociais e econômicas na atualidade, levou as companhias seguradoras a formularem variadas modalidades de seguros.

Com base na regulamentação da Susep, os seguros encontram-se hoje divididos por grupos e ramos, sendo esses últimos os seguintes: patrimonial; responsabilidades; automóvel; transportes; riscos financeiros; pessoas coletivo; habitacional; rural; pessoas individual; marítimos; aeronáuticos; microsseguros; petróleo; nucleares; saúde; aceitações do exterior; sucursais no exterior.

Desta forma, podemos observar como os seguros estão cada vez mais presentes em todas as esferas da sociedade, abarcando indivíduos em sua vida privada, bem como dos pequenos agentes econômicos aos agentes hegemônicos, incluindo, aí, os objetos e equipamentos técnicos que controlam (veículos, imóveis, barragens, plataformas de petróleo etc.).

${ }^{14}$ https://www.valor.com.br/valor1000/2019/ranking50maioresseguradoras\# 
A contratação dos seguros divide-se em duas modalidades: facultativa e obrigatória. Os seguros de contratação obrigatória estão apresentados no DecretoLei 73, de 21 de Novembro de 1966, em seu artigo 20. Assim, é importante dizer que as companhias de seguros contam com um mercado garantido por força da legislação ${ }^{15}$.

Vale frisar ainda que o setor de seguros possui diversos canais de distribuição, dentre os quais: pequenos e médios corretores independentes; grandes corretoras nacionais e internacionais; assessorias de seguros; rede bancária por parceria; rede bancária própria; internet direto; call center direto; varejo e lojas (KPMG, Jan/2013). Neste contexto, "o canal de vendas de seguros mais importante do mercado continua a ser o de corretores independentes, com uma representação estimada de 80 a $85 \%$ da receita desse setor"; neste canal, predomina a venda de seguros para o ramo automóvel (ibid.).

Assim, esta atividade não se capilariza apenas em relação à distribuição dos riscos, mas, também, espacialmente, constituindo uma extensa e densa rede no território.

No que se refere ao mercado de resseguros, após a quebra do monopólio do IRB (Instituto de Resseguros do Brasil), ${ }^{16}$ houve grande expansão no setor; até junho de 2011, existiam 94 resseguradoras e 32 corretoras de resseguros autorizadas a operar no território brasileiro (DELLOITE, 2011). Já em 2014, o número de resseguradoras que atuavam no Brasil saltou para 123 no total. (GALIZA, $2015)^{17}$.

Conforme dados expostos no Portal CNseg (2017, p.01) ${ }^{18}$, atuam no Brasil 134 resseguradoras, estando divididas da seguinte forma: Local (16); Eventual (81); Admitida (37). Grosso modo, estes três grupos de resseguradoras podem ser caracterizados da seguinte maneira (Quadro 02):

\footnotetext{
${ }^{15}$ Além dos seguros obrigatórios dispostos no Decreto-Lei 73, outros foram criados com o passar do tempo. São eles: Seguro de Danos Pessoais Causados por Veículos Automotores de Via Terrestre DPVAT; Seguro de Danos Pessoais de Embarcações ou suas Cargas - DPEM; Seguro de Acidentes de Trabalho - SAT; Seguro Habitacional do Sistema Financeiro da Habitação - SFH; Seguro de Responsabilidade Civil dos Transportadores relativo aos danos pessoais provocados aos usuários dos serviços de transporte rodoviário interestadual e internacional; Seguro Carta Verde. Portal Tudosobreseguros. Disponível em: https://www.tudosobreseguros.org.br/tipos-de-seguros/ .

${ }_{16}$ Criado no final dos anos 1930 por Getúlio Vargas, o IRB (empresa estatal de economia mista) manteve o monopólio do mercado brasileiro de resseguros até meados dos anos 2000 , quando houve a abertura deste mercado a outras resseguradoras de origem nacional ou transnacional. Neste contexto de abertura de mercado, o IRB foi convertido em empresa privada, embora o Estado ainda possua ações da empresa, dentre as quais uma Golden Share - Ação de Classe Especial - que garante a este o poder de veto em algumas decisões relativas à empresa.

${ }_{17}$ Estudo realizado pela Rating de Seguros Consultoria a pedido da Terra Brasis Resseguros.

${ }^{18}$ http://cnseg.org.br/
} 
Quadro 02 - Tipos de Resseguradoras - Características Principais

\begin{tabular}{|l|l|}
\hline \multicolumn{1}{|c|}{ Tipos } & \multicolumn{1}{c|}{ Características } \\
\hline Local & - Ressegurador sediado no país. \\
\hline \multirow{4}{*}{ Admitida } & - Ressegurador sediado no exterior, com escritório de representação no \\
& $\begin{array}{l}\text { País } \\
\text { - Operações no país de origem há mais de cinco anos } \\
\text { - Patrimônio Líquido não inferior a US\$ } 100 \text { milhões } \\
\text { - Ser portador de classificação de solvência com nível mínimo de } \\
\text { classificação de risco. }\end{array}$ \\
\hline \multirow{5}{*}{ Eventual } & $\begin{array}{l}\text { - Resseguradora sediada no exterior, sem escritório de representação } \\
\text { no País } \\
\text { - Operações no país de origem há mais de cinco anos } \\
\text { - Patrimônio Líquido não inferior a US\$ } 150 \text { milhões } \\
\text { - Ser portador de classificação de solvência com nível mínimo de } \\
\text { classificação de risco. }\end{array}$ \\
\hline
\end{tabular}

Fonte dos Dados: Susep (2018, p.01) ${ }^{19}$, Resolução CNSP ․ํ 330, de $2015^{20}$.

Em 2011, o mercado de resseguros no Brasil era estimado em US $\$ 2,5$ bilhões (KPMG, 2011). Já em 2014, os prêmios emitidos em resseguros atingiram $\mathrm{R} \$ 9,1$ bilhões (GALIZA, 2015).

Retomando o ranking apresentado pelo Jornal Valor Econômico, podemos evidenciar as 15 maiores companhias de resseguros (em prêmios emitidos líquidos) atuantes no território brasileiro em 2018. (Quadro 03).

Quadro 03 - As 15 Maiores Companhias de Resseguros - Brasil/2018

\begin{tabular}{|c|c|c|c|}
\hline Classificação & Companhia & Sede & $\begin{array}{c}\text { Prêmios Emitidos } \\
\text { Líquidos (em R\$ } \\
\text { milhões) }\end{array}$ \\
\hline 1 & IRB-Brasil Re * & RJ & $6.035,5$ \\
\hline 2 & Munich Re do Brasil & SP & 614,9 \\
\hline 3 & Swiss RE Brasil & SP & 426,8 \\
\hline 4 & Austral Resseguradora & RJ & 391,8 \\
\hline 5 & Allianz Global Resseguros & RJ & 338,7 \\
\hline 6 & BTG Pactual Resseguradora & RJ & 329,4 \\
\hline 7 & SCOR Brasil & $\mathrm{RJ}$ & 317,3 \\
\hline 8 & Zurich Resseguradora & SP & 292,4 \\
\hline
\end{tabular}




\begin{tabular}{|c|l|c|c|}
\hline 9 & Junto Resseguros $^{1}$ & PR & 238,7 \\
\hline 10 & Chubb Resseguradora & SP & 218,3 \\
\hline 11 & AXA Corporate & SP & 217,5 \\
\hline 12 & Mapfre RE do Brasil & SP & 184,0 \\
\hline 13 & Terra Brasis Resseguros & SP & 146,5 \\
\hline 14 & AIG Resseguros Brasil & SP & 96,1 \\
\hline 15 & Markel Resseguradora & RJ & 76,7 \\
\hline
\end{tabular}

* Balanço Consolidado. / ${ }^{1}$ Atual denominação social de J. Malucelli Resseguradora S.A.

Fonte: Valor Econômico'21

No estudo realizado pela consultoria Rating de Seguros, a pedido da Terra Brasis Resseguros (com 24 resseguradoras), pode-se comprovar as considerações apresentadas anteriormente em relação às características da mão-de-obra utilizada pelas empresas do setor (Tabela 01).

Tabela 01 - Resseguradoras - Grau de Escolaridade dos Funcionários (\%)

\begin{tabular}{l|c|c}
\hline Nível & Admitidas & Locais \\
\hline Pós Graduação & 39 & 49 \\
\hline Nível Superior & 55 & 41 \\
\hline Nível Médio & 4 & 9 \\
\hline Nível Fundamental & 0 & 0 \\
\hline Demais & 2 & $\mathbf{1 0 0}$ \\
\hline Total & $\mathbf{1 0 0}$ & \\
\hline
\end{tabular}

Fonte: Galiza (2015) - Rating de Seguros Consultoria

Os dados apresentados na tabela acima mostram que mais de $90 \%$ dos funcionários das resseguradoras que participaram da pesquisa possuem curso superior (muitos deles com pós-graduação).

Finalmente, a análise dos dados apresentados até o momento mostra como as companhias seguradoras e resseguras vêm expandindo sua atuação no território brasileiro, seja pela demanda do mercado, seja pelo arcabouço normativo que impõe a contratação de determinados seguros.

Mais do que isso, podemos observar o alto grau de transnacionalização que esta atividade possui no Brasil, contribuindo, assim, para que os nexos do sistema financeiro global estejam cada vez mais presentes no território nacional.

\section{Alguns Agentes do Setor de Seguros e Resseguros e a Divisão Territorial do Trabalho no Brasil}

${ }^{21}$ https://www.valor.com.br/valor1000/2019/rankingmaioresresseguros 
Os dados apresentados nos Quadros 01 e 03, sobre as companhias de seguros e resseguros, evidenciam o alto grau de concentração das sedes destas empresas no território brasileiro (GAMARRA, TREVISAN, 2018).

Das 15 maiores companhias de seguros (Prêmio Emitido Líquido - 2018) atuantes no território brasileiro, 10 estão localizadas no Estado de São Paulo.

Já a análise dos dados relativos à localização das sedes das 15 maiores resseguradoras que atuam no território brasileiro, indica a presença de 8 delas no Estado de São Paulo.

Uma questão importante desta análise é que, embora a maior parte das companhias de seguros e resseguros esteja sediada no Estado de São Paulo, esta atividade se capilariza por todo o território brasileiro por meio de escritórios regionais e, principalmente, por meio dos corretores de seguros (entre outros agentes e instituições ligadas ao setor).

Assim, a existência de modernas redes telemáticas é imprescindível para a coleta, processamento e transmissão de dados, informações e capitais pelo território nacional.

Os fluxos, de todo tipo - das mercadorias às informações pressupõem a existência de redes. A primeira propriedade das redes é a conexidade - qualidade de conexo -, que tem ou em que há conexão, ligação. Os nós das redes são assim lugares de conexões, lugares de poder e de referência, como sugere RAFFESTIN. (DIAS, 2006, p.148).

No caso da atividade seguradora, com o suporte das redes técnicas, conforma-se uma rede de serviços que capta recursos de todo o território (por meio dos prêmios pagos) o os colocam sob o comando de seguradoras e resseguradoras que estão fortemente sediadas nos estados de São Paulo e Rio de Janeiro.

Considerando que grande parte das sedes das empresas do setor financeiro (seguradoras, resseguradoras, bancos, bolsa de valores etc.) localiza-se no Estado de São Paulo e, de modo mais específico, na metrópole paulista, podemos considerar ainda que esta atividade (financeira) ajuda a reforçar a onipresença da cidade de São Paulo no território nacional (SANTOS, 2005).

Cabe destacar ainda que a rede formada a partir das companhias e dos corretores de seguros e resseguros contribui enormemente com a expansão do meio técnico-científico-informacional, bem como com a financeirização do território brasileiro no período atual. 
Hoje, as companhias do setor de seguros e resseguros (incluindo corretoras) encontram-se organizadas em pelo menos quatro importantes associações: CNseg - Confederação Nacional das Empresas de Seguros Gerais, Previdência Privada e Vida, Saúde Suplementar e Capitalização (que engloba a FenaCap, FenaPrevi, FenaSaúde e Fenseg); $A B C S I$ - Associação Brasileira de Companhias de Seguro Internacionais; FENABER - Federação Nacional das Empresas de Resseguros; Fenacor - Federação Nacional dos Corretores de Seguros Privados e de Resseguros, de Capitalização, de Previdência Privada, das Empresas Corretoras de Seguros e de Resseguros.

As associações, vale dizer, se constituem em um importante lugar de convergência de interesses do setor, buscando legitimar o discurso das empresas associadas junto à sociedade em geral (TREVISAN, 2007).

Assim, tais associações se constituem em importantes centros produtores de informações sobre o setor, por meio da elaboração de levantamentos estatísticos, estudos e relatórios; além disso, nos sites das associações estão disponíveis informações sobre empresas associadas, legislação que regulamenta o setor, glossários etc.

As associações contribuem, ainda, organizando e divulgando feiras e eventos do setor, onde são debatidas e difundidas informações sobre o mercado de seguros/resseguros.

Outra questão importante relacionada às associações diz respeito à organização de eventos de premiação; neste contexto, as empresas premiadas passam a agregar valor à sua marca, colocando-se numa posição de destaque no mercado.

Algumas associações (como é o caso da CNseg, FenaPrevi e FunenSeg), possuem cursos e programas de certificação técnica para seguradoras e profissionais; tais certificações, ao mesmo tempo que buscam aprimorar os serviços prestados, também acabam dando destaque aos "certificados", se constituindo em uma importante ferramenta de marketing.

Como apontado anteriormente, as companhias do setor de seguros e resseguros demandam profissionais qualificados e especializados. Com o intuito de suprir parte desta demanda (as companhias absorvem profissionais de diversas áreas), o setor também conta com um centro de formação especializado, a FunenSeg - Fundação Escola Nacional de Seguros. 
Fundada na década de 1970, a FunenSeg oferece Curso de Habilitação de Corretores de Seguros, Cursos Técnicos, Cursos de Graduação (bacharelado e tecnólogo), Cursos de Pós-Graduação, MBA, EAD e Cursos Preparatórios para Exames de Certificação Internacional.

Finalmente, nos chama a atenção o fato de a maior parte das entidades mencionadas acima (exceto a ABCSI, com sede em São Paulo) possuir sede na cidade do Rio de Janeiro, onde também se encontra a sede da Susep; vale dizer que, embora a Susep esteja sediada no Rio de Janeiro, ela se constitui numa autarquia federal, cuja administração é exercida por um Superintendente nomeado pelo Presidente da República.

Desta forma, os dados expostos nos ajudam a compreender como se processa a divisão territorial do trabalho neste setor; assim, Brasília (sede do Governo Federal), a área polarizada por São Paulo (sede da maioria das principais companhias de seguros e resseguros do mercado) e a área polarizada pelo Rio de Janeiro (sede de importantes seguradoras e resseguradoras, bem como de entidades representativas do setor) aparecem como pontos nodais desta rede que, como dito anteriormente, se capilariza pelo território por meio da atuação dos diversos agentes que compõem o setor.

\section{Considerações Finais}

No período atual, a informação se constitui em uma mercadoria estratégica para os agentes hegemônicos e, também, em elemento impulsionador de uma nova divisão social e territorial do trabalho (setor quaternário da economia).

Neste contexto, a atuação das companhias de seguros e resseguros (por meio da transferência de riscos e oferta de garantias) ajuda a conformar uma nova dinâmica e novos usos do território.

Tomando como base o território brasileiro, visualizamos que a divisão territorial do trabalho neste setor tem nas áreas polarizadas por São Paulo, Rio de Janeiro e Brasília os centros nodais desta complexa rede.

Finalmente, vale destacar que esta atividade (seguros/resseguros) se capilariza por todo o território por meio dos inúmeros agentes que compõem o setor, estabelecendo, assim, uma rede que capta recursos de todos os lugares (por meio dos prêmios pagos pelos segurados) e os centralizam em companhias cujas sedes estão, em grande medida, na região concentrada do território brasileiro (sobretudo São Paulo e Rio de Janeiro). 


\section{REFERÊNCIAS}

CASTILLO, R. Sistemas Orbitais e Uso do Território: integração eletrônica e conhecimento digital do território. São Paulo: DG-FFLCH-USP, 1999. Tese de Doutorado em Geografia.

CASTILLO, R.; FREDERICO, S. Espaço Geográfico, Produção e Movimento: uma reflexão sobre o conceito de circuito espacial produtivo. Revista Sociedade \& Natureza, Uberlândia, 22 (3): 461-474, dez. 2010.

DANTAS, Marcos. A Lógica do Capital Informação. Rio de Janeiro: Contraponto, 2002.

DANTAS, Marcos. Trabalho com informação: valor, acumulação, apropriação nas redes do capital. Rio de Janeiro: Centro de Filosofia e Ciências Humanas da UFRJ (CFCH-UFRJ), 2012.

DELLOITE. A Indústria de Seguros no Brasil: transformação e crescimento em um país de oportunidades. 2011.2 Disponível em:

http://www2.deloitte.com/content/dam/Deloitte/br/Documents/financialservices/LivrolndustriaSegurosPortugues.pdf . Acesso em: 23/10/2014.

DIAS, L. C. Redes: emergência e organização. In: I. E. de Castro et al. (orgs.). Geografia: conceitos e temas. Rio de Janeiro: Bertrand Brasil, 2006.

FREIRE, C. T. Um Estudo sobre os Serviços Intensivos em Conhecimento no Brasil. In. João Alberto de Negri e Luis Cláudio Kubota (orgs). Estrutura e Dinâmica do Setor de Serviços no Brasil. Brasília: IPEA, 2006.

GALIZA, F. Análise Econômica do Mercado de Resseguro no Brasil. Estudo encomendado a Rating de Seguros Consultoria pela Terra Brasis Resseguros. Maio/2015. Disponível em: http://www.ratingdeseguros.com.br/pdfs/estudoresseguro2015.pdf . Acesso em: 16/02/2016.

GAMARRA, E. U.; TREVISAN, L. O Setor de Resseguros e os Círculos de Cooperação no Território Brasileiro. Revista Brasileira de Iniciação Científica. v. 5, n. 2, 2018.

KON, A. Sobre as Atividades de Serviços: revendo conceitos e tipologias. Revista de Economia Política, v.19, n.2 (74), abril-junho/1999.

KPMG. Abertura do Mercado de Resseguro no Brasil: percepções do mercado. 2011. Disponível em: https://www.kpmg.com/BR/PT/Estudos Analises/artigosepublicacoes/Documents/FinancialServices/Abertura do Mercado de Resseguro no Brasil.pdf . Acesso em: 23/10/2014.

KPMG. Situação Atual e Perspectivas do Mercado de Distribuição de Seguros no Brasil. Jan/2013. Disponível em: http:/www.kpmg.com/BR/PT/Estudos Analises/artigosepublicacoes/Documents/Seguros/sit uacao-atual-mercado-seguros.pdf . Acesso em: 23/10/2014.

LÉVY, P. A Revolução Contemporânea em Matéria de Comunicação. Revista FAMECOS. Porto Alegre, N.9, Dez/1998.

MAGALHÃES, R. de A. O Mercado de Seguros no Brasil. Rio de Janeiro, FUNENSEG, 1997.

MENDONÇA, A. P. Temas de Seguro. São Paulo: Editora Roncarati, 2010.

MONTALBÁN, M. V. Inquérito à Informação. Lisboa: Iniciativas Editoriais, 1971.

PORAT, M. U. The Information Economy: Definition and Measurement. Office of Telecommunications (DOC) ,Washington,D.C. 1977.

SANTOS, M. A Natureza do Espaço: técnica e tempo - razão e emoção. São Paulo: Edusp, 2002. 
SANTOS, M. A Urbanização Brasileira. São Paulo: Edusp, 2005.

SILVA, A. M. B. da. A Contemporaneidade de São Paulo. Produção de informações e novo uso do território brasileiro. São Paulo: DG-FFLCH-USP, 2001. Tese de Doutorado.

SILVA, A. M. B. da. A Nova Divisão Territorial Brasileira e a Produção de Informações na Cidade de São Paulo (as empresas de consultoria). In: Santos, M.; Silveira, M. L. O Brasil: território e sociedade no início do século XXI. Rio de Janeiro: Record, 2005.

SILVA, A. M. B. da. Círculos de Informações, Urbanização, e Usos do Território Brasileiro. Revista da ANPEGE, v.8, n.10, p.3-15, ago/dez 2012.

TOMELIM, Mário. O Quaternário: seu espaço e poder. Brasília, Ed. UNB, 1988.

TREVISAN, L. Os Operadores Logísticos e o Uso do Território Brasileiro: racionalidade e fluidez aos circuitos espaciais de produção. Campinas: DGEO-IG-UNICAMP, 2007. Dissertação de Mestrado.

\section{NOTAS DE AUTOR}

\section{CONTRIBUIÇÃO DE AUTORIA}

Leandro Trevisan - Concepção. Coleta de dados, Análise de dados, Elaboração do manuscrito, revisão e aprovação da versão final do trabalho.

\section{FINANCIAMENTO}

Edital Ciências Humanas e Sociais. Chamada MCTI/CNPq/MEC/CAPES № 22/2014. Processo: 471876/2014-3.

\section{CONSENTIMENTO DE USO DE IMAGEM}

Não se aplica.

\section{APROVAÇÃO DE COMITÊ DE ÉTICA EM PESQUISA \\ Não se aplica.}

\section{CONFLITO DE INTERESSES}

Não se aplica.

\section{LICENÇA DE USO}

Este artigo está licenciado sob a Licença Creative Commons CC-BY. Com essa licença você pode compartilhar, adaptar, criar para qualquer fim, desde que atribua a autoria da obra.

\section{HISTÓRICO}

Recebido em: 06-02-2019

Aprovado em: 23-10-2020 